\title{
Mulher, Trabalho e Direito Internacional: entre a desigualdade e a inefetividade das normas trabalhistas
}

\author{
Women, Work and International Law: \\ between inequality and ineffectiveness of labor standards
}

\section{Luis Paulo Ferraz de Oliveira}

Graduando em Direito pela Universidade do Estado da Bahia UNEB. Estagiário do Ministério Público do Estado da Bahia - MPE/ BA. Integrante do Grupo de Pesquisa Labedire - Laboratório de Estudos do Direito e do Discurso (CNPq). Membro do Grupo de Estudos em Direito do Trabalho do Conselho Consultivo da Jovem Advocacia da Ordem dos Advogados do Brasil da Seccional Bahia $\mathrm{OAB} / \mathrm{BA}$, em parceria com a Liga Acadêmica de Estudos Jurídicos da Bahia - LAEJU/BA. Membro da Rede Brasileira Direito e Literatura - RDL. E-mail: luispauloferraz.direito@gmail.com.

\section{Luciano de Oliveira Souza Tourinho, PhD}

Pós-doutor em Direitos Humanos (Direitos Sociais) pela Universidad de Salamanca. Doutor em Direito Público - Direito Penal pela Universidade Federal da Bahia. Professor Adjunto de Direito Penal e Direito Processual Penal na Universidade Estadual do Sudoeste da Bahia - UESB. Mestre em Direito Público - Direito Penal pela Universidade Federal da Bahia - UFBA. Especialista em Direito Público e em Ciências Criminais pela Faculdade Independente do Nordeste. Graduado em Direito pela UESB. E-mail: luciano.tourinho@uesb.edu.br.

RESUMO: Essa pesquisa tem como escopo refletir juridicamente acerca do lugar da mulher no meio ambiente de trabalho, que se revela de extrema importância no atual Estado Constitucional Democrático de Direito, tendo em vista a perpetuação da dominação masculina, do machismo e do patriarcado engessado na sociedade há séculos na história, e que reflete diretamente na mulher no mercado de trabalho. A discriminação de gênero no momento de contratação e, principalmente, durante a execução do contrato de trabalho, no tocante a promoção, cargo na empresa e lugar de fala, ainda é uma realidade fática no Brasil. Nesse sentido, investiga-se a condição da mulher ao longo da história como forma de entender o cerne da desigualdade entre a mulher e o homem nos postos de trabalho. Ainda, sob o viés do Direito Internacional, examina-se os contributos da Organização Internacional do Trabalho - OIT, na busca por uma igualdade material

Laborare. Ano III, Número 5, Jul-Dez/2020, pp. 107-129. ISSN 2595-847X. https://revistalaborare.org/ DOI: https://doi.org/10.33637/2595-847x.2020-60 
de gênero nas relações trabalhistas para, a partir disso, interpretar os motivos determinantes e o contexto histórico de cada Convenção Internacional sobre o trabalho da mulher. Para sua investigação, é desenvolvida pesquisa bibliográfica e exploratória, por meio de revisão teórica, de cunho indutivo, a partir de obras consolidadas pela crítica nacional, bem como de textos legislativos, Convenções da OIT e da Constituição Federal. Nesse sentido, espera- se tornar esse trabalho de fundamental importância para a comunidade acadêmica e social, a fim de dar concretude aos direitos trabalhistas da mulher e construir um pensamento jurídico emancipador.

Palavras-chave: discriminação; machismo; mercado de trabalho; organização internacional do trabalho; trabalhadora.

\begin{abstract}
The scope of this research is to reflect legally on the place of women in the work environment, which is extremely important in the current Democratic Constitutional State of Law, in view of the perpetuation of male domination, machismo, and patriarchy plastered in society for centuries of history, and which reflects directly on the labor market of women. Gender discrimination at the time of hiring and, especially, during the execution of the labor contract, regarding promotion, position in the company and place of speech, is still a factual reality in Brazil. In this sense, one investigates the condition of women throughout history as a way to understand the core of the inequality between women and men in the jobs. Also, under the bias of International Law, the contributions of the International Labor Organization - ILO, in the search for material gender equality in labor relations are examined to interpret the determining motives and historical context of each International Convention on Women's Work. For its research, bibliographic and exploratory research is developed, by means of theoretical revision, of inductive nature, based on works consolidated by national critics, as well as legislative texts, ILO Conventions and the Federal Constitution. In this sense, it hopes to become this work of fundamental importance to the academic and social community, in order to give concreteness to women's labor rights and build an emancipating legal thought.
\end{abstract}

Keywords: discrimination; machism; labor market; international labor organization; labor.

\title{
INTRODUÇÃO
}

A condição da mulher ao longo da história decorreu de várias transformações jurídicas, políticas e sociais. Sempre relegada nos espaços públicos, a mulher carrega a marca da desigualdade de gênero, que humilha, segrega, discrimina e adoece o ser

Laborare. Ano III, Número 5, Jul-Dez/2020, pp. 107-129. ISSN 2595-847X. https://revistalaborare.org/ DOI: https://doi.org/10.33637/2595-847x.2020-60 
feminino. A presente pesquisa, ademais, expõe que a dominação masculina reflete diretamente no mercado de trabalho da mulher, na medida em que o pensamento de inferioridade do sexo feminino ainda está presente no seio social.

A mulher encontra embaraços desde a contratação para postos de trabalho, bem como na execução da relação empregatícia, notadamente no tocante aos cargos, que são direcionados, em sua grande maioria, ao sexo masculino. Ainda, a mulher é anulada no lugar de fala dentro da empresa, que discrimina inclusive na questão da remuneração, mesmo diante de trabalho de igual valor.

É nessa perspectiva que a análise sobre o lugar da mulher no mercado de trabalho ganhou espaço na Organização Internacional do Trabalho (OIT), que editou diversas Convenções e Recomendações para erradicar a desigualdade de gênero no ambiente de trabalho, assim como estabeleceu diretrizes de atuação para os Estados-membros efetivarem a igualdade material no direito do trabalho. Contudo, a discriminação e a inefetividade das normas trabalhistas para as mulheres ainda é uma realidade vivenciada pela classe feminina.

Nesse contexto, questiona-se: em que medida os instrumentos normativos da Organização Internacional do Trabalho têm contribuído para a erradicação da desigualdade de gênero no mercado de trabalho, após um longo avanço na legislação brasileira de proteção da mulher no meio ambiente laboral?

Para responder a tal questionamento, foi desenvolvida pesquisa bibliográfica e exploratória, de cunho indutivo, a partir da análise histórica e crítica do direito posto pelo Estado, ou seja, artigos de leis, decretos, tratados internacionais e da Constituição Federal, e também de obras que dialogam com a temática central.

Ademais, feitas essas considerações iniciais sobre a distinção temática, tal como da problemática e da metodologia do trabalho, é importante destacar que o estudo será iniciado com a condição da mulher ao longo da história como forma de descortinar os processos que se moldaram e se constituíram até se chegar ao Estado Democrático de Direito, com ampla previsão legal de proteção às mulheres.

Em seguida, passa-se à análise dos esforços da Organização Internacional do Trabalho para combater a discriminação contra a mulher no mercado de trabalho, assim como da inefetividade das normas trabalhistas e da persistência da discriminação de gênero na realidade fática das relações laborais.

Laborare. Ano III, Número 5, Jul-Dez/2020, pp. 107-129. ISSN 2595-847X. https://revistalaborare.org/ DOI: https://doi.org/10.33637/2595-847x.2020-60 


\section{A CONDIÇÃO DA MULHER AO LONGO DA HISTÓRIA: DA INTOLERÂNCIA À PROTEÇÃO NO PLANO LEGAL}

A condição da mulher na sociedade perpassou por várias transformações ao longo da história. Desde a Antiguidade Clássica, a própria situação feminina situava-se num contexto de submissão e inferioridade frente ao universo masculino. Relegada no espaço público e principalmente político, a luta por direitos de cidadania conflitava com a sociedade patriarcal estabelecida durante séculos da história (BOURDIEU, 2012, p. 32-44).

Para compreender o lugar da mulher no meio ambiente de trabalho, mister se faz retornar aos primórdios da existência humana e analisar o processo de constituição do sujeito como pessoa, seus grupos, discursos, bem como as classes sociais que se constituíram ao longo da história. À figura feminina, desde o embrionário processo de urbanização das cidades e da composição dos lares, foram dispensadas funções um tanto exóticas, ora degradantes ora de total submissão ao lar e o que as distinguiam era o seu porte físico, assim como a cor da sua pele, sendo dominadas por um sentimento inferior de feminilidade (BEAUVOIR, 1970, p. 7-23).

O papel desempenhado pela mulher restringia-se aos cuidados domésticos (aqui, considera-se uma visão mais ampla a incluir, além dos serviços da casa, o cuidado com os filhos e, principalmente, com as regras postas pelo marido), de modo a manter o equilíbrio matrimonial, subjugando aos preceitos culturais e religiosos como forma de estruturar um modelo familiar engessado, sem muita ou quase nenhuma transformação (BOURDIEU, 2012, p. 45-55).

Por outro lado, "em contraste com a mulher branca, exaltada como santa ou musa, a bestialização da "mãe preta" e a exacerbação da sexualidade da "mulata" são imagens fartamente exploradas nas representações sociais" (CARNEIRO, 2006, p. 46-51), isso tendo em vista que há séculos as mulheres têm sido prisioneiras dos estereótipos construídos pela classe dominante, ou seja, a mulher era vista como mero instrumento para satisfação de serviços degradantes à mercê do gênero dominante, notadamente a mulher negra.

A mulher dessa época de extrema aniquilação de qualquer tipo de igualdade ou mesmo direito no ordenamento jurídico, como liberdade e dignidade, era reduzida como objeto de dominação masculina, recebendo, assim, um termo de "não-função", ou seja, de nenhuma influência na vida cotidiana da sociedade e do trabalho. A sua única função era o desempenho das sobreditas atividades domésticas, estabelecida

Laborare. Ano III, Número 5, Jul-Dez/2020, pp. 107-129. ISSN 2595-847X. https://revistalaborare.org/ DOI: https://doi.org/10.33637/2595-847x.2020-60 
culturalmente pelos agentes sociais (Estado, igreja, família), até a atualidade (CARNEIRO, 2006, p. 46-51).

O papel da mulher como esposa e do lar está engessado na sociedade há séculos, isso porque o trabalho externo era de incumbência do pai, irmão, marido, o que abriu margem para o acúmulo de bens da classe dominante, tornando, assim, a mulher ainda mais dependente e submissa, pois "as mulheres só podem aí ser vistas como objetos, ou melhor, como símbolos cujo sentido se constitui fora delas e cuja função é contribuir para a perpetuação ou o aumento do capital simbólico em poder dos homens" (BOURDIEU, 2012, p. 55). Assim, o ambiente de trabalho ainda era um sonho a ser conquistado pela classe feminina.

Ao analisar as contribuições de Parker nos estudos sobre a condição da mulher na história, Silva expõe que "as atividades do homem eram dirigidas para o mundo social mais amplo da economia, política e interações sociais, [...] enquanto os de sua mulher eram rigidamente restringidos, limitavam-se ao mundo doméstico da própria família" (SILVA, 2000, p. 9). Conclusão, para o homem o mundo, para a mulher o lar e sem espaço para questionamentos.

Foi somente a partir do século XVIII, com o marco da Revolução Francesa, que se percebe um tímido, mas importante avanço no processo de institucionalização dos direitos das mulheres. Determinados benefícios relacionados aos direitos civis foram sendo conquistados pela classe dominada, como o direito à herança, ao divórcio, contudo o direito ao voto e à igualdade para o trabalho ainda foram excluídos. A cidadania, assim, revelava-se fragilizada para a mulher.

Então, sob o ponto de vista da história linear, o sentimento de impotência, sujeição, inferioridade, e até mesmo de "não-função" por parte das mulheres abriu margem para o início de diversas manifestações que buscaram resguardar os direitos das mulheres em igualdade com a classe dominante. A Revolução Francesa abriu a verdadeira "caixa de pandora" para o que futuramente viria a ser entendido como direito da mulher ser livre e igual na sociedade, notadamente no meio ambiente laboral, pelo menos no seu aspecto formal.

Houve, assim, uma releitura do papel social da mulher por parte da própria comunidade feminina que objetivava a construção de uma identidade da mulher na sociedade. $\mathrm{E}$ isso se deve ao sentimento de esgotamento com tamanha sujeição ao patriarcado dominante há muito tempo (NICKNICH, 2016, p. 369). A mulher precisava, pois, colocar em prática seus desejos profissionais obscuros e aniquilados pela classe opressora.

Laborare. Ano III, Número 5, Jul-Dez/2020, pp. 107-129. ISSN 2595-847X. https://revistalaborare.org/ DOI: https://doi.org/10.33637/2595-847x.2020-60 
E foi no epicentro dos calorosos debates durante a Revolução Francesa que Olympes de Gouges, ativista política e feminista, escreveu a Declaração dos Direitos da Mulher e da Cidadã em 1791. O documento era um manifesto público em favor dos direitos das mulheres e contra os valores patriarcais pregados pelo Estado, pela igreja e pela família. Foi, sim, um divisor de águas na busca por espaço da mulher para além das barreiras domésticas, ao prever, por exemplo, que a mulher nasce livre e tem os mesmos direitos do homem, e que as distinções sociais só podem ser baseadas no interesse comum.

Os valores difundidos pela Revolução Francesa permeou o pensamento do "eu feminino" de forma paulatina, inspirando mulheres à luta por mais direitos democráticos e, principalmente, ao entendimento de que a mulher pode ser livre para viver em sociedade da forma que lhe convém, livre de qualquer estereótipo ou coerção dos agentes sociais.

Nessa perspectiva, com o avanço das manifestações feministas em busca do reconhecimento de direitos de igualdade, liberdade e dignidade, bem como por espaço no meio laboral, que só foram possíveis após o entendimento de que a mulher é essencialmente igual ao homem, foi possível rebater o status subalterno do ser feminino historicamente engessado na sociedade, contradizendo o argumento de Tomás de Aquino que "é indubitável que a mulher se destina a viver sob o domínio do homem e não tem por si mesma nenhuma autoridade", citado por Beauvoir. (BEAUVOIR, 1970, p. 119).

"As mulheres não podem senão tornar-se o que elas são segundo a razão mítica, confirmando assim, e antes de tudo a seus próprios olhos, que elas estão naturalmente destinadas ao baixo, ao torto, ao pequeno, ao mesquinho, ao fútil, etc." (BOURDIEU, 2012 , p. 41). Esse era um pensamento que não mais podia ser aceito pela sociedade, principalmente após um longo avanço nos anos da história até se chegar ao Estado Democrático de Direito no Brasil.

$\mathrm{Na}$ tentativa de buscar compreender a formação do pensamento machista de submissão da mulher às regras postas pelo gênero dominante, bem como a discriminação existente no ambiente de trabalho, pode-se recorrer às abordagens filosóficas do teórico social Michel Foucault com a finalidade de analisar como as relações de saber e poder segregam e excluem as pessoas mais vulneráveis, como é tratado aqui, com enfoque no trabalho da mulher.

Laborare. Ano III, Número 5, Jul-Dez/2020, pp. 107-129. ISSN 2595-847X. https://revistalaborare.org/ DOI: https://doi.org/10.33637/2595-847x.2020-60 
Em seu livro Microfísica do Poder, de 1979, Foucault propõe a compreensão de como as relações de poder produzem verdades que se veiculam através dos discursos que atravessam a mente dos sujeitos (FOUCAULT, 1984, p. 5-15). Sob o ponto de vista da dominação masculina sobre a mulher, é isso que ocorre: os agentes sociais (Estado, igreja, família) institucionalizaram na sociedade o pensamento de que à mulher incube as tarefas domésticas e de cuidado para com os filhos e o marido, pois assim está prescrito na bíblia, o que retira a possibilidade de igualdade para a mulher ser profissionalmente aceita e respeitada nos diversos segmentos da sociedade. Essa é a verdade do discurso posto há séculos da história e que justificou diversas atrocidades cometidas contra as mulheres.

Foucault acrescenta outra metodologia de regimes do poder: o regime de verdade que faz funcionar em cada sociedade. Através de uma política geral de verdades, tem-se a existência de discursos, os quais são atribuídos como verdadeiros. E esses discursos são produzidos para tentar justificar o pensamento dos atores sociais que ditam as regras do convívio social (FOUCAULT, 1984, p. 10-15). Importante salientar que, para o autor, as relações de saber e poder estão em todas as camadas da sociedade e não somente nas mãos do Estado. Por isso, a discriminação contra a mulher é pregada, também, pelo setor trabalhista, pela igreja e pelas famílias.

É como Foucault esclarece em seus estudos: o poder não se encontra concentrado em um soberano restritamente, assim como, o poder também não é uma relação entre dominador e dominados, mas sim é um exercício que circula em conformidade com o conjunto de aparelhos, instituições e regulamentos que aplicam o direito e que produzem verdades e saberes (FOUCAULT, 1984, p. 103-105). Está, pois, o discurso machista de segregação do ambiente de trabalho para o homem respaldado nesse conjunto de agentes sociais que intimidam as mulheres.

Ao tratar das instituições que atuam no sentido de materializar a subordinação das mulheres ao universo masculino na sociedade há séculos, Bourdieu, inicialmente, certifica que "É, sem dúvida, à família que cabe o papel principal na reprodução da dominação e da visão masculinas; que se impõe a experiência precoce da divisão sexual do trabalho e da representação legítima dessa divisão, garantida pelo direito e inscrita na linguagem" (BOURDIEU, 2012, p. 103). Ou seja, o discurso da verdade sobre a dominação masculina, disseminado na sociedade e implantado na mente das mulheres, começa no seu núcleo familiar, muitas vezes porque aquele ambiente já reproduz a marca do machismo estrutural de costumes passados.

Ainda, segundo o autor, há a presença de outra instituição acentuadamente mais contundente na propagação do pensamento dominador de que à mulher nada e ao

Laborare. Ano III, Número 5, Jul-Dez/2020, pp. 107-129. ISSN 2595-847X. https://revistalaborare.org/ DOI: https://doi.org/10.33637/2595-847x.2020-60 
homem o mundo "Quanto à Igreja, marcada pelo antifeminismo profundo de um clero pronto a condenar todas as faltas femininas à decência, ela inculca (ou inculcava) explicitamente uma moral familiarista, [...] dominada pelo dogma da inata inferioridade das mulheres" (BOURDIEU, 2012, p. 103-104). É, pois, uma instituição completamente dominada pelos valores patriarcais de extrema sujeição da mulher ao marido e ao lar, assim como aos filhos, pois a mulher deve cumprir sua função bíblia de procriação, para eles.

E por falar em textos bíblicos, as mulheres pensaram por muito tempo que o discurso dominador imposto pelas sobreditas instituições era, na verdade, o que Deus determinou para elas, pois a igreja age "sobre as estruturas históricas do inconsciente, por meio, sobretudo da simbólica dos textos sagrados, da liturgia e até do espaço e do tempo religiosos" [...] (BOURDIEU, 2012, p. 103-104). A classe feminina, então, foi historicamente moldada a pensar que sua tarefa no mundo era aquela imposta pela igreja, pela família, sem possibilidade de questionamento, pois a interpretação distorcida dos textos bíblicos intimidava qualquer tipo de pensamento libertador.

Contudo, esse pensamento precisava mudar. Abaixo o pensamento dominador. No Brasil, final do século XVIII, já se encontravam relatos de mulheres que lutavam em busca da conquista por direitos mínimos. Ideias avançadas à época se evidenciavam em torno das benesses da educação, tendo-a como fator preponderante para a luta libertária das amarras patriarcais e sobre uma posição social das mulheres, defendida por autoras como Nísia Floresta, que foi criadora da primeira escola para mulheres. Marcando um cenário industrial anarco-sindicalista, em 1917 a professora Deolinda Daltro liderou uma passeata exigindo a extensão do voto às mulheres, crivando, assim, uma ideologia "pré-feminista" que se fortaleceria nas décadas subsequentes.

Feitas essas considerações pontuais acerca da condição da mulher ao longo da história, que é importante para compreender o cerne do problema que envolve a discriminação da mulher no ambiente de trabalho, cumpre agora tecer alguns comentários no tocante à evolução jurídica dos direitos da mulher no Brasil. Essa análise revela-se de extrema magnitude para entender o processo histórico construído pela luta das mulheres em favor da igualdade de gênero no trabalho e da suplantação de discriminações e discursos de ódios, respaldados pelo pensamento dominador engessado pelas instituições na sociedade.

Pode-se identificar a raiz da proteção constitucional à mulher na primeira Constituição Federal, datada de 1824, que em seu artigo 179, inciso XIII, assegurou formalmente a igualdade de todos "a Lei será igual para todos, quer proteja, quer

Laborare. Ano III, Número 5, Jul-Dez/2020, pp. 107-129. ISSN 2595-847X. https://revistalaborare.org/ DOI: https://doi.org/10.33637/2595-847x.2020-60 
castigue, o recompensará em proporção dos merecimentos de cada um" (BRASIL, 1824). Esse, pois, seria o primeiro germe do direito fundamental à igualdade no constitucionalismo brasileiro, conforme as lições preciosas de Paulo Bonavides (BONAVIDES, 1969).

Essa previsão se manteve na Constituição de 1891 , no artigo 72 , $\S 2^{\circ}$ e, embora não houvesse menção expressa às mulheres, estas foram alvos, pelo menos no plano legal, com o direito de serem consideradas iguais em relação às demais pessoas. Restava, pois, a eficácia de tal direito no plano social. Já a Carta de 1934 assegurou às mulheres o direito ao voto, um grande divisor de águas na luta pela cidadania feminina, assim como proibiu qualquer tipo de discriminação por motivo de sexo, até mesmo com relação ao pagamento de salários, uma vez que no quesito relação de trabalho a mulher ainda era vítima de discriminação.

E assim perdurou nas Constituições seguintes que, paulatinamente, passaram a institucionalizar mais direitos fundamentais individuais e sociais às mulheres, como a assistência médica e sanitária à mulher gestante, antes e depois do parto e sem prejuízo do salário, direito este assegurado ainda no primeiro governo de Getúlio Vargas, se estendendo- se pelas Constituições de 1937, 1946, 1967 e na Emenda de 69.

Contudo, foi somente com a redemocratização do País que a luta vitoriosa do movimento feminista se concretizou de forma mais categórica. Isso foi possível graças à passagem neoconstitucionalista, firmada após as atrocidades cometidas na Segunda Guerra Mundial que pautou suas ações com fundamento legal e interpretação literal. Assim, a institucionalização de direitos fundamentais ocorreu com a promulgação da Constituição Federal de 1988, um divisor de águas no pensamento democrático do Estado, na medida em que prestações positivas passaram a ser exigidas do Estado, a fim de dar concretude a dignidade da pessoa humana, bem como garantir o cidadão na sua liberdade, necessidade e preservação (BARROSO, 2010, p. 43-45).

Iniciou-se, então, o Estado Constitucional Democrático de Direito, marcado pelo fenômeno atual de constitucionalização dos ramos do direito, bem como da força normativa da Constituição, que buscou reconhecer a supremacia material e axiológica da Carta Política de 1988 (CUNHA JÚNIOR, 2019, p. 34-35). Agora, o Estado não mais poderia se omitir frente ao patriarcado historicamente presente na história, na medida em que a Assembleia Nacional Constituinte estabeleceu, entre outros, diversas diretrizes de atuação do Estado para solucionar um problema histórico de

Laborare. Ano III, Número 5, Jul-Dez/2020, pp. 107-129. ISSN 2595-847X. https://revistalaborare.org/ DOI: https://doi.org/10.33637/2595-847x.2020-60 
dominação masculina, inferioridade da mulher e sua discriminação nos postos de trabalho.

A exemplo disso, pode-se citar algumas passagens da Lei Maior de 1988 que respondeu aos clamores do movimento feminista em busca por direitos e cidadania, como a garantia de isonomia jurídica entre homens e mulheres, notadamente no âmbito familiar; a proibição de discriminação no mercado de trabalho por motivo de sexo, o que protegeu a mulher com regras específicas de acesso ao trabalho; o reconhecimento do planejamento familiar como uma decisão livre do casal e, principalmente, o dever do Estado coibir a violência no âmbito das relações familiares, como ocorreu com a criação da Lei Maria da Penha (Lei n. ${ }^{\circ} 11.340$ de 2006), com vistas a proteger a mulher do machismo engessado na sociedade; bem como o direito das presidiárias de amamentarem seus filhos, sendo a maternidade um direito social, entre tantas outras conquistas (BRASIL, 1988).

Para mais, o art. $7^{\circ}$ da Carta Política de 1988 estabeleceu diversos direitos sociais do trabalho amplamente aplicáveis às mulheres, a fim de protegê-las no acesso igualitário ao trabalho, bem como na preservação do emprego e condução das atividades, pois mais salutar do que possibilitar tal acesso é garantir a permanência da mulher nesse ambiente. Ademais, alguns incisos foram direcionados à mulher como forma de igualar sua condição particular ao gênero masculino, pois somente assim é possível materializar a verdadeira lei da igualdade material, que será tratada no próximo capitulo, a exemplo do inciso XVIII do art. $7^{\circ}$ que prevê a "licença à gestante, sem prejuízo do emprego e do salário, com a duração de cento e vinte dias", e inciso XX que garante a "proteção do mercado de trabalho da mulher, mediante incentivos específicos, nos termos da lei” (BRASIL, 1988).

Já lecionava Reale $(2002$, p. 299) "há casos em que é necessário abrandar o texto, operando-se tal abrandamento através da equidade, que é, portanto, a justiça amoldada à especificidade de uma situação real". Foi imbuída desse pensamento democrático da igualdade de cidadania que as mulheres se fizeram ouvidas pela Assembleia Constituinte de 1988, e se fazem até hoje em busca por mais espaço na sociedade e reconhecimento dos seus direitos, principalmente, o de ser livre, livre de qualquer tipo de discriminação no ambiente de trabalho e livre dos discursos de verdades impostos pelas instituições que ditam as regras do convívio social.

Contudo, muito embora tenha ocorrido uma mudança no plano legal dos direitos das mulheres no aspecto do ambiente de trabalho, ainda existe a dominação masculina perpetrada pelo Estado, pela igreja, pelas famílias e pelas empresas ou empregadores,

Laborare. Ano III, Número 5, Jul-Dez/2020, pp. 107-129. ISSN 2595-847X. https://revistalaborare.org/ DOI: https://doi.org/10.33637/2595-847x.2020-60 
na medida em que o machismo já se estruturou na sociedade, relevando-se de difícil ou quase impossível anulação, o que ainda legitima a permanência da discriminação da mulher no trabalho. Conforme as lições de Santos "a revolução democrática do direito e da justiça só faz verdadeiramente sentido no âmbito de uma revolução mais ampla que inclua a democratização do Estado e da sociedade" (SANTOS, 2011, p. 16).

Assim, a mudança na legislação revelou-se insuficiente e formalista para uma verdadeira promoção da igualdade material de gênero nos postos de trabalho, na medida em que no plano factual o desrespeito ao perfil feminino no ambiente laboral ainda é perpetuado, como ocorre na diferenciação de salários, cargos e lugar de fala entre o homem e a mulher.

Ao analisar o problema em torno da efetividade das normas jurídicas no plano social, Muricy assevera que "Para além - ou para aquém... - do direito posto, existe um conjunto de crenças, máximas de opinião, instituições, enfim, um conjunto de "certezas" não problematizadas [...] (MURICY, 2015, p. 102). São essas certezas que impedem a justa aplicação dos direitos trabalhistas das mulheres, assim como conduzem à perpetuação da dominação do homem sobre a mulher, o que coloca em xeque tanto avanço social e jurídico de respeito e igualdade da classe feminina.

Portanto, o grande desafio na atualidade não é a institucionalização de mais direitos trabalhistas para as mulheres, em que pese as necessidades por melhorias de condições no meio ambiente laboral, mas sim o devido respeito e efetividade dos diplomas já existente, a fim de promover a igualdade material entre os trabalhadores, independentemente do gênero em questão.

\section{A PROTEÇÃo do TRABalHo DA MULHER PELA ORGANizAÇÃo INTERNACIONAL DO TRABALHO: IGUALDADE SUBSTANCIAL}

A Organização Internacional do Trabalho (OIT) ${ }^{1}$, fundada em 1919, logo após as atrocidades cometidas durante a Primeira Guerra Mundial (1914-1918), é agência vinculada à Organização das Nações Unidas (ONU), que objetiva promover a justiça social no meio ambiente de trabalho para gerações do presente e do futuro. Desde a sua criação, a OIT fomentou um pensamento democrático do direito do trabalho, a

\footnotetext{
1 Desde a sua criação, os membros tripartites da OIT adotaram 188 Convenções Internacionais de Trabalho e 200 Recomendações sobre diversos temas (emprego, proteção social, recursos humanos, saúde e segurança no trabalho, trabalho marítimo etc.). Em 1998, a Conferência Internacional do Trabalho aprovou a Declaração dos Princípios e Direitos Fundamentais no Trabalho, que estabelece quatro princípios fundamentais a que todos os membros da OIT estão sujeitos: liberdade sindical e reconhecimento efetivo do direito de negociação coletiva; eliminação de todas as formas de trabalho forçado; abolição efetiva do trabalho infantil; eliminação de todas as formas de discriminação no emprego ou na ocupação (OIT, 2020).
}

Laborare. Ano III, Número 5, Jul-Dez/2020, pp. 107-129. ISSN 2595-847X. https://revistalaborare.org/ DOI: https://doi.org/10.33637/2595-847x.2020-60 
fim de corrigir anos de escravidão e exploração do labor humano, o que foi acompanhado, em partes, pelos Estados-membros da Organização.

Nas lições de Cunha Júnior (2019, p. 497-499), os direitos humanos e os direitos fundamentais não possuem a mesma categorização, na medida em que os primeiros são de amplitude universal e os segundos de caráter interno, mas ambos se complementam. É nesse sentido que os instrumentos normativos da OIT, que são direitos humanos em matéria do trabalho, potencializaram a carga valorativa dos direitos fundamentais previstos na Carta Política vigente no Brasil, para proteger o trabalhador em sua existência e dignificação do trabalho moderno.

É nessa perspectiva que Godinho (2017, p. 65), ao analisar os contributos da OIT no direito interno, assevera que:

"Não obstante, o Direito Internacional do Trabalho, desde seu surgimento em 1919 com a fundação da Organização Internacional do Trabalho pelo Tratado de Versalhes, e, considerada sua estruturação, principalmente em torno das Convenções da OIT, tem mantido e até incrementado sua influência no âmbito interno das realidades normativas nacionais e, até mesmo, comunitárias. Nas últimas décadas, em face da acentuação da globalização e da influência crescente de certa perspectiva internacional no interior das sociedades nacionais, a força do Direito Internacional do Trabalho tem se elevado".

O Brasil é signatário das convenções e recomendações da OIT desde 1950, quando passou a adotar seus instrumentos normativos internacionais na legislação brasileira, tendo ampliado o rol de direitos e deveres nas relações de trabalho. E com o meio ambiente de trabalho da mulher não foi diferente. O tema ganhou espaço nos textos normativos com o objetivo de equilibrar a mão de obra de trabalho e anular a discriminação de gênero no ambiente laboral, mesmo com a persistência da dominação masculina.

Dessa forma, os instrumentos normativos da Organização Internacional do Trabalho são internalizados pelo Brasil, com o finco de dar concretude aos direitos fundamentais trabalhistas previstos na Carta Política de 1988, haja vista que o Direito é uma ciência em constante evolução e que precisa atualizar seus diplomas de acordo com cada momento histórico. E assim acontece com o Direito do Trabalho, considerando as novas tendências das relações laborais que são criadas a cada momento e, principalmente, o enfrentamento de problemas ainda não solucionados, como o da discriminação da mulher no meio ambiente de trabalho.

Laborare. Ano III, Número 5, Jul-Dez/2020, pp. 107-129. ISSN 2595-847X. https://revistalaborare.org/ DOI: https://doi.org/10.33637/2595-847x.2020-60 
Cumpre, agora, tecer uma breve análise dos diplomas da OIT que trataram de resguardar o direito da mulher no trabalho em plenitude de igualdade com o sexo masculino, para, em seguida, analisar a realidade vivenciada no plano factual pela classe feminina. Tal investigação se mostra de extrema importância na construção do pensamento crítico sobre a mulher no trabalho e o trabalho da mulher, temas presentes nos debates para uma verdadeira democratização do Estado no século atual.

Historicamente, as primeiras convenções da Organização Internacional do Trabalho em matéria de direito do trabalho da mulher foram as de n. $^{\circ} 3$ e 4, datadas de 1919, logo no início de criação da agência e no epicentro dos calorosos debates da primeira onda do movimento feminista, que teve como objetivo alcançar a igualdade de direitos políticos e civis para as mulheres.

A Convenção n. ${ }^{\circ} 3$ regulamentou a garantia de emprego da mulher ${ }^{2}$ antes e depois do parto, na medida em que a trabalhadora gestante não possuía nenhuma proteção legal durante e após o período gestacional, o que colocava em xeque o trabalho da mulher e o sustento da família. Esse diploma foi ratificado pelo Brasil em 26 de abril de 1934 e promulgado para todos os efeitos por meio do Decreto $n .^{\circ} 423$, de 12 de novembro de 1935.

Essa previsão foi considerada um grande divisor de águas na vida das trabalhadoras, visto que a gravidez era motivo de demissão em massa e dificultava a contratação de mulheres para os postos de trabalho. Agora, a mulher passou a ser protegida contra a despedida sem justa causa pelo simples fato de estar grávida ou, em outros casos, contra o desligamento depois do período de repouso.

O mesmo diploma, em seu art. $3^{\circ}$, proibiu a mulher de trabalhar durante seis semanas depois do parto, mas com direito a uma indenização para sua manutenção ${ }^{3}$, o que futuramente viria a ser entendido e institucionalizado como licença maternidade

\begin{abstract}
2 Artigo 20: Para a aplicação da presente Convenção, o termo "mulher" designa toda a pessoa do sexo feminino, qualquer que seja a idade ou a nacionalidade, casada ou não, e o termo "filho" designa, todo o filho, legitimo ou não (OIT, 1919).

3 Artigo 3ㅇ da mesma Convenção: "Em todos os estabelecimentos industriaes ou commerciaes, publicos ou privados, ou nas suas dependencias, com excepção dos estabelecimentos onde só são empregadas os membros de uma mesma familia, uma mulher a) não será autorizada a trabalhar durante um periodo de seis semanas, depois do parto; b) terá 0 direito de deixar o seu trabalho, mediante a exbibição de um attestado medico que declare esperar-se o parto, provavelmente dentro em seis semanas; c) receberá, durante todo o periodo em que permanecer ausente, em virtude dos paragraphos (a) e (b), uma indemnização sufficiente para a sua manutenção e a do filho, em bôas condições de hygiene; a referida indemnização, cujo total exacto será fixado pela autoridade competente em cada paiz, terá dotada pelos fundos publicos ou satisfeita por meio de um systema de seguros. Terá direito, ainda, aos cuidados gratuitos de um medico ou de uma parteira. Nenhum erro, da parte do medico ou da parteira, no calculo da data do parto, poderá impedir uma mulher de receber a indemnização, á qual tem direito a contar da data do attestado medico até áquella em que se produzir o parto; d) terá direito em todos os casos, si amamenta o filho, duas folgas de meia hora que lhe permittam o aleitamento".
\end{abstract}

Laborare. Ano III, Número 5, Jul-Dez/2020, pp. 107-129. ISSN 2595-847X. https://revistalaborare.org/ DOI: https://doi.org/10.33637/2595-847x.2020-60 
Mulher, Trabalho e Direito Internacional: entre a desigualdade e a inefetividade das normas trabalhistas

remunerada. No Brasil, tal obrigação gerou grande insatisfação pela classe empregadora que, diante desse novo direito da mulher, passou a ter que garantir o trabalho da mulher gestante em sua plenitude.

Doravante, a Convenção n. . $^{4}$ estabeleceu a proibição da mulher, independentemente da idade, de trabalhar no período noturno como forma de preservar a sua integridade, nos dizeres da cúpula diretiva da OIT. Dessa forma, a mulher não mais poderia laborar durante a noite em estabelecimento privado ou público, exceto se trabalhasse com os membros de uma mesma família e na mesma empresa ${ }^{4}$. Esse diploma também fora promulgado pelo Brasil por meio do Decreto n. ${ }^{\circ}$ 423, de 12 de novembro de 1935.

Já a Convenção n. ${ }^{\circ} 100$ da OIT, elaborada em meados de 1953, dispôs sobre a igualdade de remuneração entre homens e mulheres no mercado de trabalho, por ofício executado de igual valor ${ }^{5}$. O instrumento foi promulgado no País pelo Decreto n. ${ }^{\circ}$ 41.721, de 25 de junho de 1957. Anos depois, a Organização Internacional do Trabalho aprovou a Convenção n. ${ }^{\circ} 111$, que trata sobre a discriminação existente no mercado de trabalho, condenando, assim, a distinção, preferência ou mesmo exclusão de pessoas dos postos de trabalho motivado por raça, cor, sexo, religião, nacionalidade, entre outros motivos, que possam gerar a desigualdade de tratamento na relação empregatícia ${ }^{6}$. Esse texto também foi ratificado pelo Brasil por meio do Decreto n. ${ }^{\circ}$ 62.150, de 19 de janeiro de 1968.

Nesse sentido, diversos outros diplomas foram criados pela OIT e posteriormente ratificados pelo Brasil ao longo da história. Contudo, selecionamos as quatro Convenções estudadas acima para refletir criticamente sobre o perfil de cada texto e

4 "Sem distincção de idade, as mulheres não poderão ser empregadas durante a noite em nenhum estabelecimento industrial público ou privado, como tão pouco em qualquer dependencia de um desses estabelecimentos, excepção feita dos estabelecimentos onde são só empregados os membros de uma mesma família" (OIT, 1919).

5 Art. 1 - "Para os fins da presente convenção: a) o termo 'remuneração' compreende o salário ou o tratamento ordinário, de base, ou mínimo, e todas as outras vantagens, pagas direta ou indiretamente, em espécie ou in natura pelo empregador ou trabalhador em razão do emprego deste último; b) a expressão 'igualdade de remuneração para a mão-de-obra masculina e a mão-de-obra feminina por um trabalho de igual valor', se refere às taxas de remuneração fixas sem discriminação fundada no sexo. Art. 2 - 1. Cada Membro deverá, por meios adaptados aos métodos em vigor para a fixação das taxas de remuneração, incentivar e, na medida em que tudo isto é compatível com os ditos métodos, assegurar a aplicação a todos os trabalhadores do princípio de igualdade de remuneração para a mão-de-obra masculina e a mão-de-obra feminina por um trabalho de igual valor" (OIT, 1953).

6 Art. 1 - 1. Para os fins da presente convenção o termo "discriminação" compreende: a) toda distinção, exclusão ou preferência fundada na raça, cor, sexo, religião, opinião política, ascendência nacional ou origem social, que tenha por efeito destruir ou alterar a igualdade de oportunidade ou de tratamento em matéria de emprego ou profissão; b) qualquer outra distinção, exclusão ou preferência que tenha por efeito destruir ou alterar a igualdade de oportunidades ou tratamento em matéria de emprego ou profissão que poderá ser especificada pelo Membro interessado depois de consultadas as organizações representativas de empregadores e trabalhadores, quando estas existam, e outros organismos adequados (OIT, 1960).

Laborare. Ano III, Número 5, Jul-Dez/2020, pp. 107-129. ISSN 2595-847X. https://revistalaborare.org/ DOI: https://doi.org/10.33637/2595-847x.2020-60 
seu momento histórico, na medida em que existe distinção de tratamento com o gênero feminino como trabalhadora. No caso das Convenções de n. ${ }^{\circ} 3$ e 4 há uma norma de natureza proibitiva, que impede a mulher de trabalhar após o parto e durante o período noturno. E tal proibição existia tendo em vista o machismo engessado na sociedade, para que a mulher continuasse desempenhando o seu papel de esposa, mãe e do lar.

Essa conclusão encontra respaldo na própria Convenção n. $^{\circ} 4$, que permitia a à mulher laborar de noite acaso estivesse na companhia dos membros da mesma família e na mesma empresa. Ora, por qual motivo impedir a mulher de trabalhar nesse período sem a presença de um familiar? Ou permitir com a presença deste? Isso revela o quanto o pensamento dominador do gênero masculino ainda era capaz de influenciar as decisões até mesmo da cúpula diretiva da Organização Internacional do Trabalho, que ao tentar proteger a mulher no mercado de trabalho, também corroborou com o patriarcado da história.

Essa deliberação da Organização Internacional do Trabalho, que foi ratificada pelo Brasil em 1935 conforme explicitado anteriormente, refletiu diretamente quando da criação da Consolidação das leis do Trabalho (CLT), em 1943, que previu em seu art. 379 "É vedado à mulher o trabalho noturno, considerado este o que for executado entre as vinte e duas (22) e as cinco (5) horas do dia seguinte" verificar que a CLT corroborou com o mesmo pensamento limitativo do direito do trabalho da mulher previsto na Convenção n. ${ }^{\circ} 4$ da OIT, porém com um tímido, mas importante avanço ao abrir exceções dessa proibição no parágrafo único do mesmo artigo.

Doravante, tal proibição recebeu diversas críticas no âmbito das academias e até mesmo dos legisladores, bem como dos movimentos feministas, até que, em 1989, a Lei n. ${ }^{\circ} 7.855$ revogou os art. 379 e 380 da CLT, que disciplinavam a proibição do trabalho noturno da mulher e, a partir de então, passou a ser plenamente possível, inclusive devendo-se observar as determinações do art. 73 do mesmo diploma quanto ao adicional noturno de $20 \%$ sobre a hora diurna (MARTINS, 2020, p. 620).

Já as Convenções de n. ${ }^{\circ} 100$ e 111, elaboradas após quase 40 anos de criação da OIT, efetivamente cumpriram seu papel democratizador de proteção da mulher no mercado de trabalho, visto que estabeleceram o direito de igual remuneração entre o homem e

7 Parágrafo único. Estão excluídas da proibição deste artigo, além das que trabalham nas atividades enumeradas no parágrafo único do art. 372: a) as mulheres maiores de dezoito (18) anos, empregadas em empresas de telefonia, rádio-telefonia ou radiotelegrafia; b) as mulheres maiores de dezoito (18) anos, empregadas em serviços de enfermagem; c) as mulheres maiores de dezoito (18) anos, empregadas em casas de diversões, hotéis, restaurantes, bares, e estabelecimentos congêneres; d) as mulheres que, não participando de trabalho contínuo, ocupem postos de direção (BRASIL, 1943).

Laborare. Ano III, Número 5, Jul-Dez/2020, pp. 107-129. ISSN 2595-847X. https://revistalaborare.org/ DOI: https://doi.org/10.33637/2595-847x.2020-60 
a mulher, bem como a igualdade de contratação e de oportunidades dentro do emprego. As duas Convenções Internacionais potencializaram a busca pela erradicação da discriminação da mulher no mercado de trabalho pelos EstadosMembros, o que abriu margem para a CLT, no Brasil, acompanhar esse avanço no tratamento da legislação no tocante à classe feminina.

Como exemplo disso, verifica-se o art. 373-A, inciso IV, da CLT, que veda a exigência de atestado ou exame de qualquer natureza para comprovação de esterilidade ou gravidez no momento da admissão ou para permanência no emprego. Para mais, imbuído do movimento em busca da proteção do mercado de trabalho da mulher da OIT, na promoção da igualdade material entre homens e mulheres, o legislador reservou um capítulo na CLT para tratar "da proteção do trabalho da mulher", com diversas diretrizes que devem ser observadas para garantir os direitos e deveres da classe feminina.

Restou notório, pois, que a Organização Internacional do Trabalho floresceu o seu pensamento no tocante a proteção do mercado de trabalho da mulher até se consolidar a verdadeira igualdade de trabalho entre os gêneros. Essa evolução decorreu das manifestações feministas por espaço de cidadania, liberdade e igualdade de direitos, notadamente no meio ambiente de trabalho.

E na legislação brasileira houve um longo avanço na temática da mulher no meio ambiente de trabalho, com a edição de textos legislativos e melhoria dos artigos da Consolidação das Leis do Trabalho. Contudo, ocorreu, também, um retrocesso social com a edição da Lei n. ${ }^{\circ}$ 13.467/17, conhecida com Reforma Trabalhista, uma vez que revogou artigos de proteção da mulher no tocante a sua jornada laboral, intervalos e trabalho em locais insalubres, bem como criou outros institutos que precarizaram o trabalho.

Isso se confirma com a revogação do art. 384 da CLT, que assegurava à mulher o direito a um intervalo de 15 minutos antes de dar início às horas extras. Nesse caso, o empregador era obrigado a conceder um descanso de quinze minutos entre o término da jornada contratada e o início da sua prorrogação. Essa norma, pois, prezava pela saúde e integridade física e mental da trabalhadora, tendo sido criticada por diversos atores sociais com o argumento de que tal previsão feria o princípio da igualdade.

O Tribunal Superior do Trabalho, em julgamento de Incidente de Inconstitucionalidade em Recurso de Revista (TST - IIN - RR - 1.540/2005-04612-00.5.), em 2008, entendeu que a concessão de condições especiais à mulher não fere o princípio da igualdade contido no art. $5^{\circ}$ da Constituição Federal de 1988. Em

Laborare. Ano III, Número 5, Jul-Dez/2020, pp. 107-129. ISSN 2595-847X. https://revistalaborare.org/ DOl: https://doi.org/10.33637/2595-847x.2020-60 
momento posterior, o Supremo Tribunal Federal confirmou esse entendimento do TST, por meio do Recurso Extraordinário - RE 658312, que firmou a tese de que o artigo 384 da CLT foi recepcionado pela Constituição da República de 1988, pois faz parte do capítulo que trata da proteção do trabalho da mulher. Nesse sentido, Godinho e Gabriela Delgado (2017, p. 148-149) concluem que:

\begin{abstract}
“As vantagens jurídicas adicionais atribuídas à mulher, pelo Direito - inclusive o Direito do Trabalho - são, conforme visto, sufragadas pela Constituição da República. Esta se voltou, como se sabe, para a eliminação da discriminação milenar arquitetada contra as mulheres na sociedade histórica, não só mediante a proibição de tratamento diferenciado com relação aos homens, como também pela agregação de vantagens adicionais específicas, fundadas em peculiaridades consideradas relevantes no que tange as razões biológicas e/ou sociológicas da mulher. A retirada de direitos das mulheres, portanto, é conduta legislativa contrária ao espírito constitucional de 1988, uma incompreensão a respeito da sociedade livre, justa e solidária que a Constituição da República quer ver instaurada no País".
\end{abstract}

Outro ponto que merece ser destacado é a mudança no tratamento destinado à mulher gestante e lactante que labora em locais insalubres. Antes da Reforma Trabalhista de 2017, essa trabalhadora era obrigatoriamente afastada do ambiente de trabalho insalubre enquanto durasse o período de gestação ou de lactação, a fim de proteger a saúde e a segurança da mãe e do seu filho em desenvolvimento. Assim, a mesma era realocada para outro setor salubre e que protegesse a gestante e o feto.

Contudo, a Lei n. $^{\circ} 13.467 / 17$ precarizou o trabalho da mulher gestante ao prever que só haveria afastamento imediato do local de trabalho nos casos de atividades insalubres em grau máximo. Acaso fosse configurado grau médio ou mínimo, o afastamento estaria condicionado à apresentação de laudo médico emitido por profissional de confiança. E no caso da trabalhadora lactante, em qualquer grau, o afastamento precisaria do laudo - art. 394-A da CLT.

Essa mudança na legislação trabalhista feriu de forma contundente a dignidade do trabalho da mulher em período gestacional ou de lactação, tendo anulado anos de avanço institucional na legislação brasileira trabalhista de proteção à trabalhadora. Tanto é assim que em 2019, dois anos após a edição da Reforma Trabalhista, o Plenário do STF reconheceu a inconstitucionalidade dessa nova regra do art. 394-A da CLT, por meio da ADIN n. ${ }^{\circ}$ 5938. Para os ministros, a nova sistemática caracterizou um grande retrocesso social e anulação dos direitos sociais das trabalhadoras.

Laborare. Ano III, Número 5, Jul-Dez/2020, pp. 107-129. ISSN 2595-847X. https://revistalaborare.org/ DOI: https://doi.org/10.33637/2595-847x.2020-60 
Ainda, com relação aos intervalos na jornada de trabalho, a Lei n. ${ }^{\circ}$ 13.467/17 passou a exigir que, para a trabalhadora usufruir dos dois intervalos intrajornada de meia hora cada para amamentar o filho de até seis meses completos, previsto no art. 396 da CLT, há a necessidade de prévio acordo entre a trabalhadora e o empregador, por meio de acordo individual de trabalho. Ora, sabe-se que o trabalhador é a parte hipossuficiente na relação empregatícia e que, na prática, deve satisfazer aos comandos diretivos e decisórios do empregador, o que coloca em xeque a real aplicação desse direito pelas trabalhadoras.

Para além desses retrocessos sociais que são perpetrados pelo Estado na legislação social trabalhista, ao anular ou modificar institutos jurídicos já consolidados, conforme se verificou acima, existe também a inefetividade, a inobservância e a ignorância das normas trabalhistas pelos atores sociais, notadamente com relação ao trabalho da mulher. Ao analisarem as implicações da Reforma Trabalhista no Estado Democrático de Direito, Godinho e Gabriela Delgado (2017, p. 39-40) afirmam que:

\footnotetext{
"A reforma trabalhista implementada no Brasil por meio da Lei n. 13.467, de 13 de julho de 2017, desponta por seu direcionamento claro em busca do retorno ao antigo papel do Direito na História como instrumento de exclusão, segregação e sedimentação da desigualdade entre as pessoas humanas e grupos sociais. Profundamente dissociada das ideias matrizes da Constituição de 1988, como a concepção de Estado Democrático de Direito, a principiologia humanística e social constitucional, o conceito constitucional de direitos fundamentais da pessoa humana no campo justrabalhista e da compreensão constitucional do Direito como instrumento de civilização, a Lei n. 13.467/2017 tenta instituir múltiplos mecanismos em direção gravemente contrária e regressiva".
}

Essa é a realidade fática que a classe feminina carrega no cotidiano e que impede a devida promoção da dignidade da pessoa humana, seja pela persistência de uma cultura religiosa e conservadora de que à mulher incube as atividades domésticas e ao homem o trabalho externo, ou mesmo diante dos discursos de que nem todo trabalho pode ser executado pela mulher, tudo isso ratificado pelo Estado.

Assim, muito embora tenha ocorrido uma mudança na legislação, hoje como muito mais direitos que outrora, devido à forte influência da OIT quando da internalização dos seus instrumentos normativos pelo Brasil, a trabalhadora ainda carrega a marca da desigualdade e da discriminação que segrega, humilha e anula os direitos trabalhistas da mulher. Isso porque ainda inexiste a igualdade substancial nas relações de trabalho. A igualdade, quando levada em consideração, é analisada sob o aspecto meramente formal da legislação.

Laborare. Ano III, Número 5, Jul-Dez/2020, pp. 107-129. ISSN 2595-847X. https://revistalaborare.org/ DOI: https://doi.org/10.33637/2595-847x.2020-60 
É necessário se pensar na igualdade material das mulheres em relação aos homens, na medida em que sua existência é tão digna quanto ao ser masculino. E tal igualdade deve-se levar em consideração as particularidades do sexo feminino para promover a verdadeira justiça social. "A regra da igualdade não consiste senão em aquinhoar desigualmente aos desiguais, na medida em que se desigualam. Nesta desigualdade social, proporcionada à desigualdade natural, é que se acha a verdadeira lei da igualdade" (BARBOSA, 1999, p. 26). Nessa exposição, Rui Barbosa clama por uma igualdade com base na desigualdade, e não fundamentada no ordenamento jurídico puro e simples. Essa é a verdadeira lei da igualdade material proposta pela Constituição da República Federativa do Brasil de 1988.

Contudo, nem sempre se pensou o princípio constitucional da igualdade sob o viés material. Em outro momento, a sua aplicação se pautava no ordenamento jurídico puro e simples, sem levar em consideração as particularidades de cada pessoa, revelando assim, a formalidade da igualdade. O constitucionalista Bastos (2001, p. 180-181) reflete com mestria que "a isonomia formal consiste no direito de todo cidadão de não ser desigualado pela lei, senão em consonância com os critérios albergados ou ao menos vedados pelo ordenamento constitucional".

O sentido da igualdade formal apoiado no normativismo passou a ser amplamente criticado ao longo dos anos, notadamente quando colocamos a questão dos direitos trabalhistas das mulheres em pauta. Por isso, a igualdade material conquistou espaço no universo jurídico para sanar um problema jurídico-social que impedia a efetiva implementação do Estado Constitucional Democrático de Direito. Não há como se pensar em igualdade formal entre o homem e a mulher no mercado de trabalho, haja vista a marca da discriminação, do machismo e do patriarcado que o sexo feminino carrega diariamente.

Dessa maneira, o que se depreende da igualdade material? Segundo os estudos de Silva (2003, p. 41) "a igualdade material ou substantiva ou substancial é aquela que assegura o tratamento uniforme de todos os homens, resultando em igualdade real e efetiva de todos, perante todos os bens da vida". Assim, tratar os desiguais de forma desigual na medida das suas desigualdades é o caminho mais justo e efetivo para promover a igualdade no plano factual, principalmente nas relações de trabalho entre os gêneros.

Mello (1993, p. 35) afirma que "o princípio da isonomia preceitua que sejam tratadas igualmente as situações iguais e desigualmente as desiguais. Donde não há como desequiparar pessoas e situações quando nelas não se encontram fatores desiguais".

Laborare. Ano III, Número 5, Jul-Dez/2020, pp. 107-129. ISSN 2595-847X. https://revistalaborare.org/ DOI: https://doi.org/10.33637/2595-847x.2020-60 
Esse é justamente o pensamento material do princípio da igualdade e que deveria ser colocado em prática pelos diversos atores da sociedade.

Contudo, mesmo com o avanço do pensamento jurídico acerca do princípio da igualdade, essa garantia nem sempre é respeitada no plano factual, o que leva a uma série de discriminações e injustiças sociais para as mulheres no mercado de trabalho. E, nos dizeres de Santos (2011, p. 16) "a revolução democrática do direito e da justiça só faz verdadeiramente sentido no âmbito de uma revolução mais ampla que inclua a democratização do Estado e da sociedade". Por isso, o respeito às normas trabalhistas da mulher e a promoção da igualdade para todos são pautas importantes na construção do pensamento democrático de efetividade dos direitos.

\section{CONSIDERAÇÕES FINAIS}

Observou-se que a condição da mulher ao longo da história foi de extrema aniquilação de direitos de cidadania, políticos e trabalhistas, na medida em que o pensamento machista e dominador do gênero masculino, bem como de instituições de poder, como o Estado e a igreja, colocou a mulher numa situação de inferioridade e desprovida de qualquer isonomia perante o sexo dominante.

A persistência de uma cultura religiosa e conservadora de que a mulher não pode desempenhar todas as atividades profissionais possíveis, assim como a disseminação de discursos de saber e de poder por diferentes atores sociais que limitam o lugar da mulher, colocam em xeque o Estado Democrático de Direito introduzido pela redemocratização do País.

Notou-se, também, que a luta feminista por espaço de cidadania e igualdade substancial para atuar em sociedade como ser livre levou a institucionalização de diversos diplomas legais protetivos dos direitos das mulheres, a fim de tentar solucionar um problema jurídico e social de atrocidades que foram cometias contra o sexo feminino.

Para mais, a Organização Internacional do Trabalho desempenhou, e de certa maneira continua a desempenhar na atualidade, um papel importante na conscientização de que a mulher é essencialmente livre e igual ao homem e que a mesma dever ser respeitada e valorizada no ambiente de trabalho, sem qualquer tipo de discriminação. Tudo isso por meio da edição de instrumentos normativos que, paulatinamente, foram ratificados pelo Brasil, o que potencializou os institutos protetivos da mulher.

Laborare. Ano III, Número 5, Jul-Dez/2020, pp. 107-129. ISSN 2595-847X. https://revistalaborare.org/ DOI: https://doi.org/10.33637/2595-847x.2020-60 
Contudo, muito embora tenha ocorrido uma mudança significativa na legislação brasileira com ampla proteção à mulher, no plano factual, tal avanço não tem sido efetivado conforme prometido pela Constituição da República Federativa do Brasil de 1988, como ocorreu com a edição da Reforma Trabalhista em 2017, que apresentou grande retrocesso social ao revogar e modificar regras destinadas à proteção da mulher no ambiente de trabalho.

Em síntese conclusiva, pode-se afirmar que é preciso uma revolução democrática do direito e do pensamento jurídico, com a finalidade de desestruturar as bases do patriarcado presente na sociedade, assim como não permitir o retrocesso social de anulação dos direitos já consagrados pela legislação.

\section{REFERÊNCIAS}

BARBOSA, Rui. Oração aos Moços. 5 ed. Rio de Janeiro: Fundação Casa de Rui Barbosa, 1999.

BARROSO, Luis Roberto. Curso de Direito Constitucional Contemporâneo. 2. ed. São Paulo: Saraiva, 2010.

BASTOS, Celso Ribeiro. Curso de direito constitucional. 22. ed. atual. São Paulo: Saraiva, 2001.

BEAUVOIR, Simone. O segundo sexo 1: fatos e mitos. Trad.: Sérgio Milliet. 4. ed. São Paulo: Difusão Europeia do Livro, 1970.

BONAVIDES, Paulo. A crise política brasileira. Rio de Janeiro: Forense, 1969.

BOURDIEU, Pierre. A dominação masculina. Trad.: Maria Helena Kühner. $11^{\circ}$ ed. Rio de Janeiro: Bertrand Brasil, 2012.

BRASIL. Constituição da República Federativa do Brasil de 1824. Disponível em: http://www.planalto.gov.br/ccivil_03/constituicao/constituicao24.htm. Acesso em: 10 Ago. 2020.

. Constituição da República Federativa do Brasil de 1988. Disponível em: http://www.planalto.gov.br/ccivil_03/constituicao/constituicao.htm. Acesso em: 10 ago. 2020 .

\begin{tabular}{cccc}
\multicolumn{1}{c}{ Leecreto-Lei $\mathbf{n}^{0}$} & 5.452, de $\mathbf{1}^{\circ}$ de maio de 1943. Aprova a Consolidação das \\
\hline Leis & Trabalho. & Disponível & em:
\end{tabular}

http://www.planalto.gov.br/ccivil_03/decreto-lei/del5452.htm. Acesso em: 20 set. 2020.

Laborare. Ano III, Número 5, Jul-Dez/2020, pp. 107-129. ISSN 2595-847X. https://revistalaborare.org/ DOI: https://doi.org/10.33637/2595-847x.2020-60 
Mulher, Trabalho e Direito Internacional: entre a desigualdade e a inefetividade das normas trabalhistas

CARNEIRO, Sueli. Estrelas com luz própria. IN: História Viva Temas Brasileiros, n. 3 - Presença Negra. São Paulo: Ediouro e Segmento-Duetto, 2006.

CUNHA JÚNIOR, Dirley da. Curso de Direito Constitucional. 13. ed. rev. ampl. e atual. Salvador: Juspodivm, 2019.

DELGADO, Maurício Godinho. Curso de direito do trabalho. 16. ed. São Paulo: LTr, 2017.

DELGADO, Mauricio Godinho; DELGADO, Gabriela Neves. A reforma trabalhista no Brasil: com os comentários à Lei n. $^{\circ}$ 13.467/2017. São Paulo: LTr, 2017.

FOUCAULT, Michel. Microfísica do Poder. 4. ed. Rio de Janeiro: Edições Graal, 1984. MARTINS, Sergio Pinto. Direito do Trabalho. 35 ed. São Paulo: Atlas, 2018.

MAZZUOLI, Valerio de Oliveira. Curso de Direito Internacional Público. $6^{\mathrm{a}}$ ed. São Paulo: Editora Revista dos Tribunais, 2012.

MELlo, Celso Antônio Bandeira de. Conteúdo jurídico do princípio da igualdade. 3. ed. São Paulo: Malheiros, 1993.

MENDES, Gilmar Ferreira; BRANCO, Paulo Gustavo Gonet. Curso de direito constitucional. $7^{\mathrm{a}}$. ed. rev. e atual. São Paulo: Saraiva, 2012.

MURICY, Marília. Senso comum e direito. São Paulo: Atlas, 2015.

NICKNICH, Mônica. O direito social das mulheres ao trabalho e o princípio da fraternidade: uma nova relacionalidade na pós-modernidade. (Tese de Doutorado em Direito). 2016.

ORGANIZAÇÃO DAS NAÇÕES UNIDAS. OIT - Organização Internacional do Trabalho. Disponível em: https://nacoesunidas.org/agencia/oit/. Acesso em: 25 Ago. 2020.

ORGANIZAÇÃO INTERNACIONAL DO TRABALHO. C003 - Convenção relativa ao Emprego das Mulheres antes e depois do parto (Proteção à Maternidade). Disponível em: https://www.ilo.org/brasilia/convencoes/WCMS_234869/lang--pt/index.htm. Acesso em: 25 ago. 2020.

Disponível

C004 - Convenção relativa ao Trabalho Noturno das Mulheres. https://www.ilo.org/brasilia/convencoes/WCMS_234871/lang--pt/index.htm. Acesso em: 25 ago. 2020.

C100 - Igualdade de Remuneração de Homens e Mulheres Trabalhadores por Trabalho de Igual Valor, de 23 de maio de 1953. Disponível:

Laborare. Ano III, Número 5, Jul-Dez/2020, pp. 107-129. ISSN 2595-847X. https://revistalaborare.org/ DOI: https://doi.org/10.33637/2595-847x.2020-60 
https://www.ilo.org/brasilia/convencoes/WCMS_235190/lang--pt/index.htm. Acesso em: 25 ago. 2020.

. C111 - Discriminação em Matéria de Emprego e Ocupação, de 15 de junho de $1960 . \quad$ Disponível em: https://www.ilo.org/brasilia/convencoes/WCMS_235325/lang--pt/index.htm. Acesso em: 25 ago. 2020.

REALE, Miguel. Lições preliminares de direito. 27. ed. São Paulo: Saraiva, 2002.

SANTOS, Boaventura de Sousa. Para uma revolução democrática da justiça. 3 . ed. São Paulo: Cortez, 2011.

SILVA, Fernanda Duarte Lopes Lucas da. Princípio constitucional da igualdade. 2. ed. Rio de Janeiro: Lumen Júris, 2003.

SILVA, Sergio Gomes da. Masculinidade na história: a construção cultural da diferença entre os sexos. Revista Psicologia, Ciência e Profissão. Brasília, v. 20, n. 3, p. 8-15, set. 2000. Disponível em: http://pepsic.bvsalud.org/scielo.php? script=sci_abstract\&pid=S1414-98932000000300003. Acesso em: 5 ago. 2020. 